\title{
Characteristics of Sulfide Stress Cracking of High Strength Pipeline Steel Weld by Heat Input
}

\author{
Byoung-Hyun Yoon*,, \\ *Rapidly Solidified Materials Research Center, Chungnam National University, Daejeon, 34134, Korea \\ †Corresponding author : byoon007@naver.com \\ (Received February 2, 2018 ; Revised February 22, 2018 ; Accepted March 28, 2018)
}

\begin{abstract}
The sulfide stress cracking (SSC) resistance of API X65 grade steel weldment has been studied using SSC test in NACE TM-0177 method A and the applied load was 72-108 \% of yield strength. The X65 grade pipe steel consisted of fine-grained ferrite and a small volume fraction of pearlite. To investigate the effect of welding process on microstructure and hardness distribution, the submerged arc welding (SAW) were performed with two electrodes. Multi pass SAW for both sides of plates was carried out with a heat input of about $59 \mathrm{~kJ} / \mathrm{cm}-100 \mathrm{~kJ} / \mathrm{cm}$. The microstructure of SAW joint was composed with ferrite, pearlite and some M-A constituent. The low carbon thermo-mechanical control process (TMCP) type steel used for SAW showed softening behavior in the HAZ adjacent to base metal. The SSC testing revealed that the API X65 SAW low heat input weld was suitable for sour service, satisfying the NACE requirements. All the specimens failed during or after SSC tests showed that the crack was initiated and propagated along the intercritical heat affected zone (ICHAZ) region as a typical stress oriented hydrogen induced cracking (SOHIC) type. By suppressing softening in the ICHAZ region, the SSC resistance of low carbon TMCP steel welded joints could be more improved.
\end{abstract}

Key Words : Sulfide stress cracking, APIX65, Submerged arc welding, Heat input, Microstructures

\section{Introduction}

While the petroleum industry holds manifold corrosive environments, corrosion costs in the oil industry are billions of dollars a year. Specifically, petroleum and natural gas system contaminated with aqueous $\mathrm{H}_{2} \mathrm{~S}$ are very aggressive to the steels used in the transport and processing of these products. In the presence of applied stress and residual stress, the failure process can occur either by sulfide stress cracking (SSC) or stress oriented hydrogen induced cracking (SOHIC) through hydrogen embrittlement. The SSC occur mainly for API linepipe grades steels ${ }^{1)}$.

The resistance of linepipe steels to SSC is related to the microstructures. Elongated $\mathrm{MnS}$ inclusions are the susceptible sites for SSC initiation as hydrogen atoms can easily accumulate at the interface between the steel matrix and non-metallic inclusions. Under the same strength level, microstructural changes from ferrite/ pearlite mixtures to tempered martensite in the steel are effective in improving its SSC resistance ${ }^{2)}$. It has been also noted that low carbon bainite of low carbon bainite/ferrite mixtures can improve the SSC resistance of the linepipe steels.

In general, the heat-affected zone (HAZ) of a weld is apt to be hardened during welding. The hardened microstructures are usually sensitive to hydrogen-induced cracking (HIC). To avoid the formation of such susceptible microstructures, the carbon equivalent or the alloying element additions are limited ${ }^{3,4)}$. Significant advances in the steel-making process have been achieved by the combination of the controlled rolling with on-line accelerated cooling process, which is generally known as thermo - mechanical control process (TMCP). The microstructures of TMCP steels could be significantly refined by rapid cooling, resulting in a remarkable improvement on strength and toughness of the steels. A residual stress effect was discussed for on SSC.

The SSC limit of smooth specimens was $46 \%$ of the ultimate tensile strength of an A106 Gr B steel pipe 
weld because of residual stress ${ }^{5)}$. Other researchers announced that the SSC limit was increased up to SMYS $90 \%$ at the uniform residual stress ${ }^{6}$.

On the other hand, the oil and gas industries have growing demand for the use of high strength low alloy (HSLA) steels due to the cost savings they afford, especially in long piping systems that transport crude oil or natural gas. Welding processes are utilized to produce pipeline segments (seam and spiral welds) and join pipeline segments (girth welds) in the field. The performance of HSLA pipeline steels in sour environments depends on the steel grade and may be strongly affected by the presence of a weld which may enhance susceptibility to SSC. An important aspect of HSLA weld hydrogen degradation is that cracking has both characteristics of SSC and stress oriented hydrogen induced cracking (SOHIC). Typically, SSC occurs in the hard $\mathrm{HAZ}$ area and is oriented perpendicular to the applied stress. SOHIC, however, occurs in the softer base material or the softened HAZ regions, which, under load, experiences strain localization owing to local softening ${ }^{7)}$.

This study focuses on the mechanical performance and SSC resistance of seam welds for pipeline segments with various heat input. In an attempt to study a low carbon equivalent TMCP type API-X65 grade steel was welded by the conventional tandem submerged arc welding, and metallurgical, mechanical and SSC characteristics were evaluated. So, the relationship between microstructure and SSC behavior of API X65 steel weldment was investigated.

\section{Experimental Procedure}

\subsection{Base metal}

A low carbon equivalent TMCP type API-X65 grade steel with a $21 \mathrm{~mm}$ thickness was used in this study. Chemical composition and mechanical strength are shown in Tables 1 and 2, respectively. The carbon content of the base metal was $0.05 \%$ and $\mathrm{Cr}$ was added to produce the ferrite of needle type. The base metal has yielded strength of $494 \mathrm{MPa}$ and tensile strength of 595 MPa.

\subsection{Welding preparation}

To investigate the effect of welding process on microstructure and hardness distribution, the submerged arc
Table 2 Mechanical properties of used steel

\begin{tabular}{|c|c|c|c|}
\hline $\begin{array}{c}\text { Thickness } \\
(\mathrm{mm})\end{array}$ & $\begin{array}{c}\text { YS } \\
(\mathrm{MPa})\end{array}$ & $\begin{array}{c}\mathrm{TS} \\
(\mathrm{MPa})\end{array}$ & $\begin{array}{c}\mathrm{vE}-15^{\circ} \mathrm{C} \\
(\mathrm{J})\end{array}$ \\
\hline 21 & 494 & 595 & 460 \\
\hline
\end{tabular}

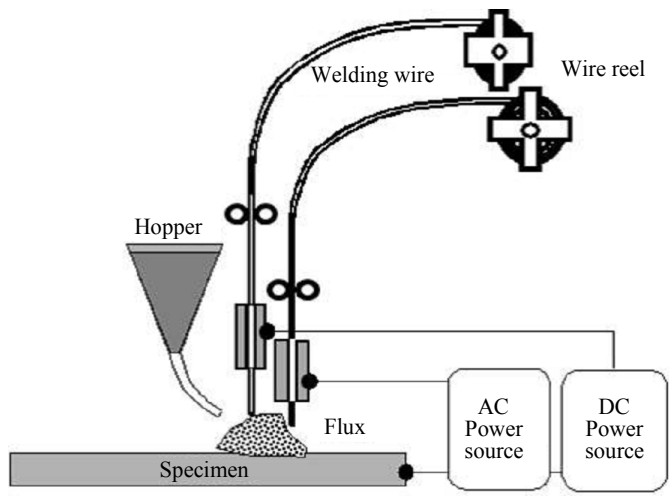

Fig. 1 Experimental configuration of submerged arc welding process used in this study

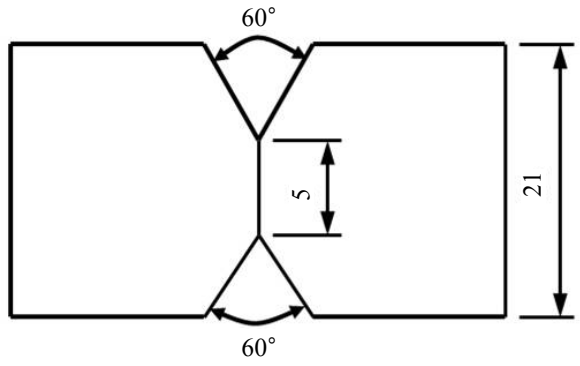

(a)

$60^{\circ}$

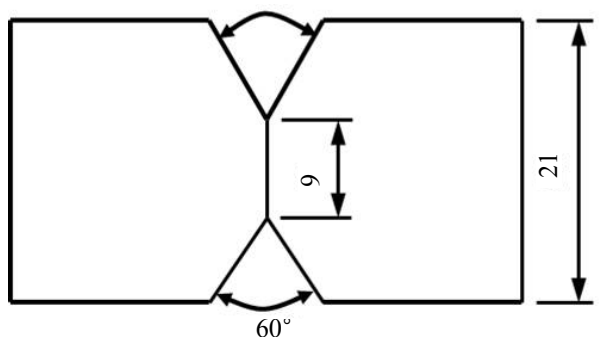

(b)

Fig. 2 Groove shape of the SAW. (a) Low heat input (b) High heat Input

welding (SAW) were performed. Fig. 1 shows the experimental configuration of SAW system with tandem electrodes. Welding conditions are shown in Table 3. Fig. 2 shows the groove morphology for the SAW process.

Table 1 Chemical composition of used steel

\begin{tabular}{|c|c|c|c|c|c|c|c|c|c|c|c|}
\hline (mass\%) & $\mathrm{C}$ & $\mathrm{Si}$ & $\mathrm{Mn}$ & $\mathrm{P}$ & $\mathrm{S}$ & $\mathrm{Ti}$ & $\mathrm{Nb}$ & $\mathrm{V}$ & $\mathrm{Cr}$ & $\mathrm{Ni}$ & $\mathrm{Cu}$ \\
\hline API X65 & 0.05 & 0.3 & 1.2 & 0.005 & 0.01 & 0.02 & 0.04 & 0.05 & 0.1 & 0.2 & 0.2 \\
\hline
\end{tabular}


Table 3 Welding conditions for submerged arc welding used in this study

\begin{tabular}{|l|c|c|c|c|}
\hline \multicolumn{2}{|c|}{} & \multicolumn{2}{|c|}{ Heat Input(kJ/cm) } & \multirow{2}{*}{ Total } \\
\cline { 3 - 5 } \multicolumn{2}{|c|}{} & DC & AC & \\
\hline \multirow{2}{*}{ Low heat input } & Inside & 15 & 13 & 28 \\
\cline { 2 - 5 } & Outside & 16 & 13 & 29 \\
\hline \multirow{3}{*}{ High heat input } & Inside & 25 & 25 & 50 \\
\cline { 2 - 5 } & Outside & 25 & 25 & 50 \\
\hline
\end{tabular}

Single pass SAW on both sides of plates was carried out with a heat input of about $15 \mathrm{~kJ} / \mathrm{cm}$ and $25 \mathrm{~kJ} / \mathrm{cm}$ per pole and a welding speed was 0.9 and $0.6 \mathrm{~m} / \mathrm{min}$, respectively.

\subsection{SSCC test}

The carbon equivalent CE (IIW) and the cracking parameter Pcm was $0.32 \%$ and $0.14 \%$, respectively. The CE parameter strongly influences the hardness of the completed weld and HAZ, which, in turn, will determine the weld suitability for sour service, according to NACE MR 0175 and TM 0177. The Pcm, on the other hand, provides a measure of resistance to weld hydrogen cracking. From these parameters, the present material was estimated to have an excellent weldability and resistance to sour service.

The sulfide stress cracking test was carried out as specified in NACE TM--0177-96 Method A (Fig. 3). Fig. 4 shows the tensile specimen used for the SSC test. The corrosion solution was solution A: $5 \mathrm{wt} \% \mathrm{NaCl}+$ $0.5 \mathrm{wt} \%$ glacial acetic acid. The test temperature was maintained at $24 \pm 3{ }^{\circ} \mathrm{C}$ and the $\mathrm{pH}$ was 2.7 - 3.5. The $\mathrm{H}_{2} \mathrm{~S}$ gas was continuously supplied at a rate of $0.5-1 \mathrm{~mL} / \mathrm{min}$ in a continuous flow throughout the experiment. The load was measured in four steps of yield strength: 72-108\%.

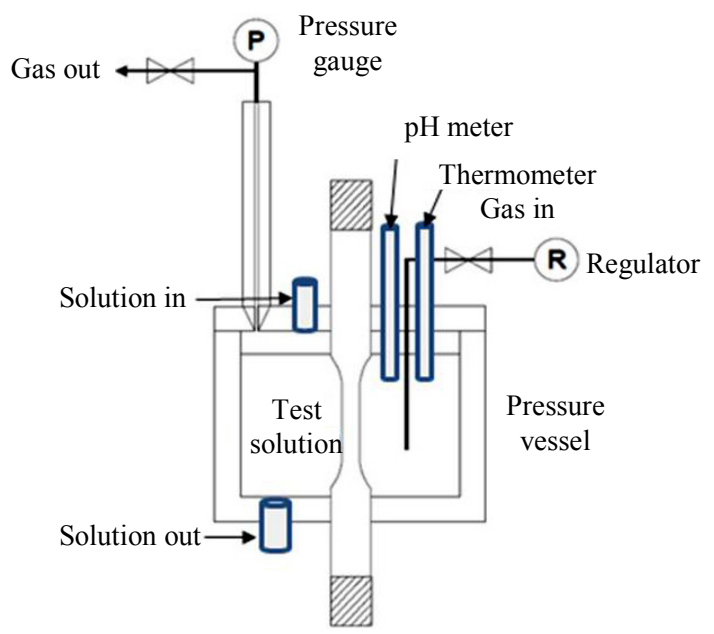

Fig. 3 Schematic arrangement of test equipment for Method A - NACE Standard Tensile Test(TMS-0177)

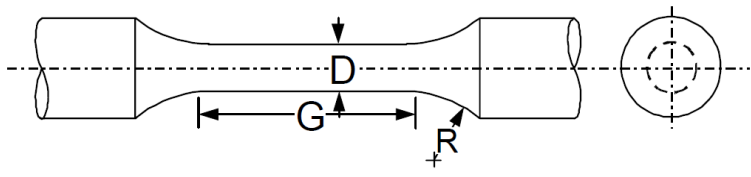

\begin{tabular}{|c|c|}
\hline Dimension $(\mathrm{mm})$ & Standard specimen \\
\hline $\mathrm{D}$ & 6.35 \\
\hline $\mathrm{G}$ & 25.4 \\
\hline $\mathrm{R}$ & 15 \\
\hline
\end{tabular}

Fig. 4 Schematic diagram of specimen for SSC test

\subsection{Microstructure evaluation}

The microstructures in welds were observed with optical microscopy using an etchant of 3\% nital solution. Hardness data were obtained from a conventional hardness tester using $5 \mathrm{~kg}$ load on weldment. After the SSC test, specimen was cut off in parallel to the tensile to observe the microstructure.

\section{Results and Discussion}

\subsection{Weld microstructures for various heat inputs}

The as-received microstructure of the X65 grade pipe steel consisted of fine-grained ferrite and a small volume fraction of pearlite as shown in the longitudinal section of Fig. 5. A heavily banded center line segregation region was not observed. This microstructure was mainly resulted from the chemical composition having a low carbon equivalent content. The fine-grained ferrite matrix containing a large fraction of newly recrystallized grains indicated that the steel experienced a thermo-mechanical processing.

Among the various microstructural regions in HSLA steel welds, coarse grain heat affected zone (CGHAZ) and inter-critical HAZ (ICHAZ) are the most concerned regions from the SSC point of view. The CGHAZ is

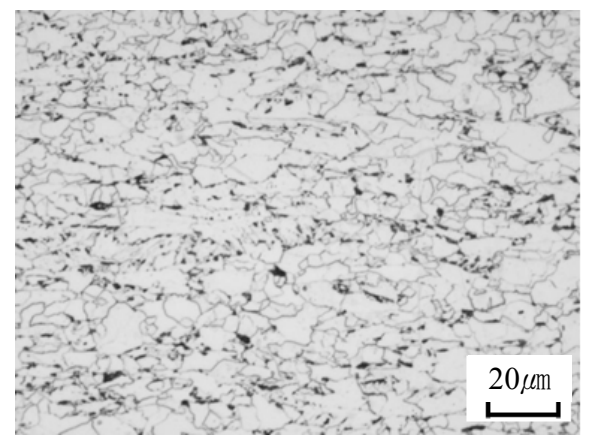

Fig. 5 A typical microstructure of base metal showing a fine grain ferrite matrix and a small fraction of pearlite 


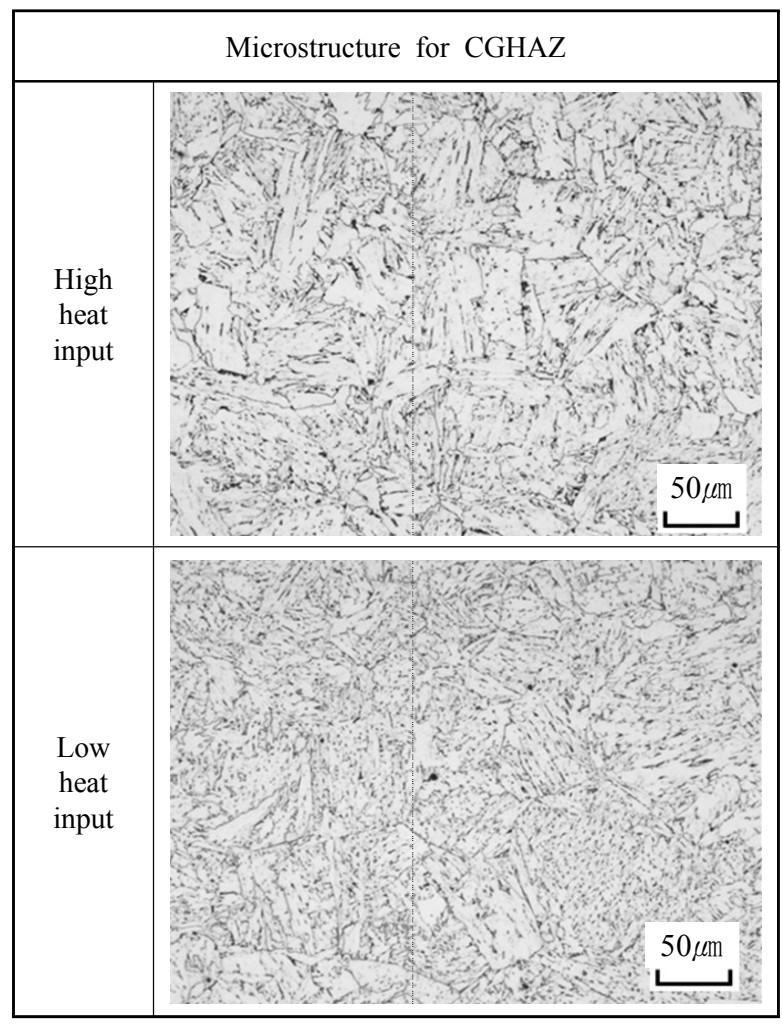

Fig. 6 Comparison of coarse grained HAZ microstructure in weldment

typically the hardest region in steel welds and closely related with the occurrence of SSC. The ICHAZ is heated into the two phase field, allowing the nucleation of small clusters of austenite in the ferrite grain boundaries. As like mentioned by Takahiro et al. ${ }^{8}$ SSC mainly occurs in this softened ICHAZ region. Therefore, the microstructures in these two regions were compared for the different welding conditions.

Fig. 6 shows microstructures of CGHAZ for each welding conditions. The CGHAZ microstructure in high heat input consisted of coarsened bainite and ferrite, while the corresponding region in low heat input was mainly composed of granular bainite. In high heat input, larger weld input energies promote longer times at elevated temperature in the CGHAZ, increasing austenite grain growth, whereas more rapid cooling rate in low heat input in conjunction with the small austenite grain size, promotes the formation of bainitic transformation products.

The microstructures in ICHAZ regions were revealed in Fig. 7. The ferrite grain size in this region appeared to be much finer than that of base metal, and at the low heat input weld appeared to be much finer than that of high heat input weld. Also, as shown in Fig. 10, the hardness of low heat input weld was little higher than that of high heat input weld at the ICHAZ region. In spite of having a finer microstructure, SSC has been

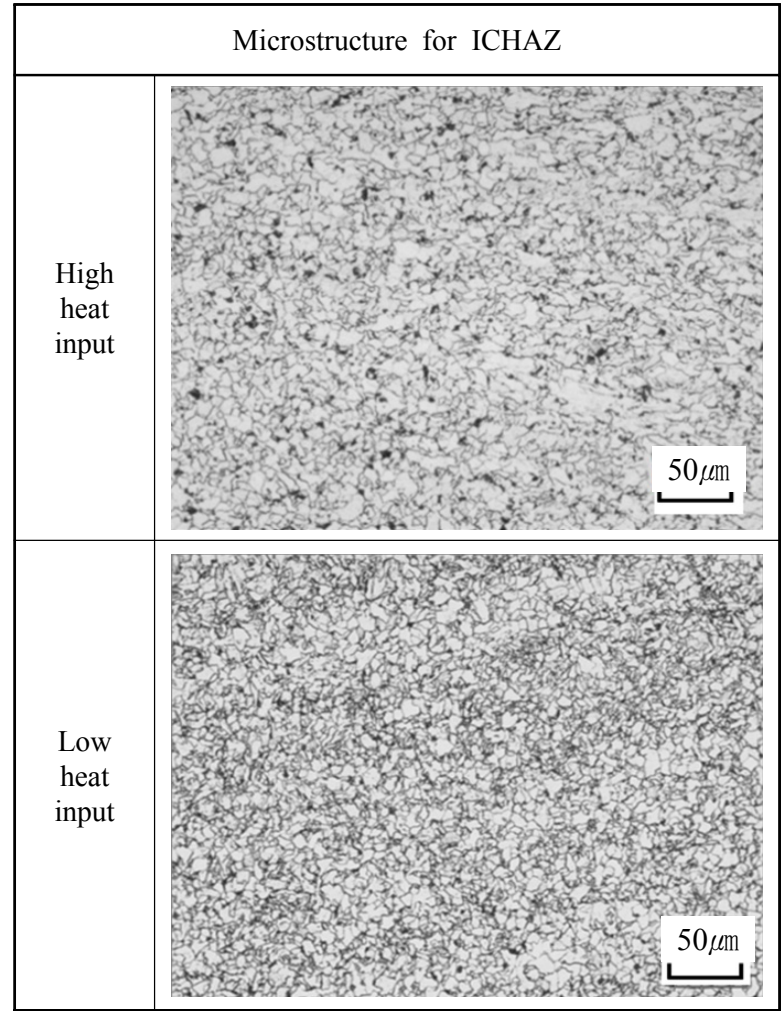

Fig. 7 Comparison of ICHAZ microstructure for each heat input

shown to occur in this softened sub and intercritical HAZ regions when the material is a low strength steel or a low carbon TMCP steel.

The microstructures of weld metal on each heat input were compared in Fig. 8. The weld metal microstructure in high heat input was typically composed of a coarsened grain boundary ferrite surrounding acicular ferrite, and a small fraction of bainite, while, in low heat input, the microstructure revealed a finer acicular ferrite surrounded by grain boundary ferrite formed along the prior austenite grain boundaries. From these microstructural evaluation for the two welding conditions, the weld metal in low heat input showed a finer microstructures than those of high heat input, which may be mainly attributed to the difference in heat input applied.

The ICHAZ can be characterized by a high tendency towards formation of Martensite - Austenite (M-A) constituent. In this study, a small fraction of the M-A constituent was observed in the ICHAZ region, 0.9 area $\%$ at low heat input and 0.2 area\% at high heat input (Fig. 9).

\subsection{Hardness distribution and softening behavior for various heat inputs}

The hardness of carbon steels currently determines their fitness for sour environments according to NACE 


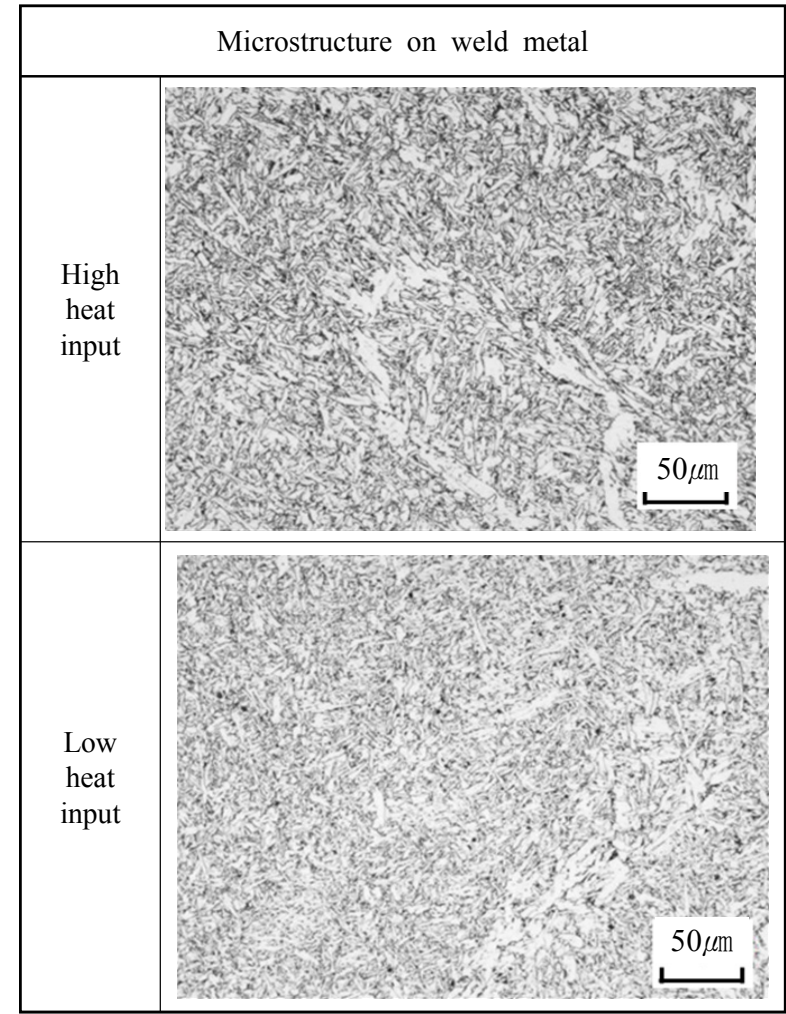

Fig. 8 Comparison of microstructure on weld metal for each heat input

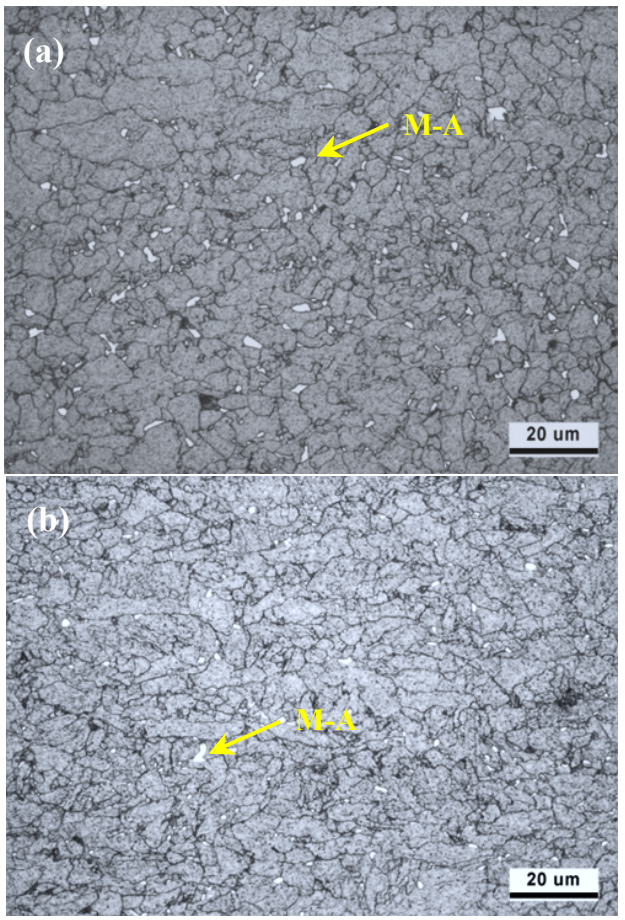

Fig. 9 Distribution of M-A constituent of ICHAZ area.
(a) Low heat input (b) High heat input

MR0175, which requires carbon steel and its weldments of a Rockwell $\mathrm{C}$ hardness (HRC) lower than 22 (equivalent to $248 \mathrm{Hv}$ ) for these applications. Steels exceeding

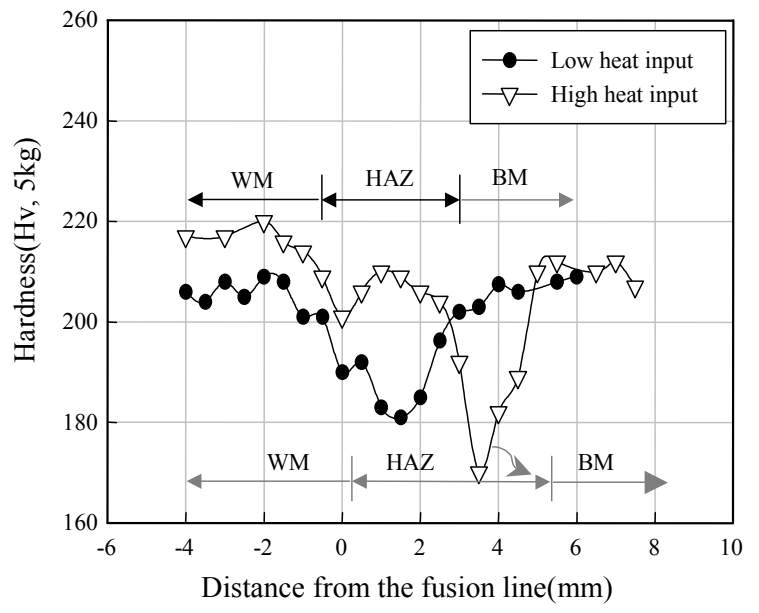

Fig. 10 Distribution of hardness across weldment for each heat input

the HRC 22 threshold are more susceptible to SSCC. On the other hand, various HAZ regions in TMCP steels are actually susceptible to softening as welding alters the thermo-mechanical history of the base metal. If the locally softened regions exist in HAZ, SOHIC could be easily happened. Therefore, hardness distribution across weldment was evaluated for the two different welds to investigate the above mentioned hardening and/or softening behavior.

Fig. 10 shows Vickers hardness distributions for each welding condition. Neither weld exceeded the Hv 248 threshold. The base metal had about Hv 200, while the hardness in weld metal was in the range of Hv 220-230. Instead of hardening in CGHAZ, softening on the HAZ near base metal occurred regardless of welding conditions. The softened region was well coincident with ICHAZ regions in each weld.

To clarify the softening behavior in ICHAZ regions, a hardness ratio of HAZ to base metal was defined for comparison. The ratio of softening on ICHAZ was about 0.86 for low heat input and 0.81 for high heat input, indicating that more severe hardness drop occurred in the high heat input weld. With regard to the different softening ratio obtained from the two welding conditions, the ferrite grain coarsening behavior in ICHAZ was considered to be one of potential reason. Smaller heat input energy in promoted shorter times at elevated temperature in the ICHAZ, prohibiting ferrite grain growth more effectively and increasing the hardness in the ICHAZ.

\subsection{SSC behavior in SAW weldment}

The presence of weldments in linepipe exposed to sour environments significantly affects their susceptibility to SSC, primarily due to localized regions of low tough- 
ness or localized strain, in combination with high residual stresses. Two types of sulfide stress cracking are observed in weldments. The first is HIC (Hydrogen Induced Cracking) inducing $\mathrm{SSC}$, which is called SOHIC (Stress Oriented HIC), second is hydrogen cracking at hard portions such as HAZ near fusion line. But the SOHIC occurs in softest region such as softened HAZ.

The SSC testing revealed that the API X65 SAW low heat input weld was suitable for sour service, satisfying the NACE requirements as shown in Fig. 11. However, in case of high heat input, specimens were failed at the ratio of $72 \%$ yield stress condition, not satisfying the NACE requirements. Fig. 12 shows the specimens after SSC test. All the specimens failed during or after SSC tests showed that the crack was initiated and propagated along the ICHAZ region as a typical SOHIC type. The fractured specimen indicated a crack path along the ICHAZ region.

Figs. 13 and 14 show the variation of pearlite and M-A constituent fractions, respectively. Pearlite is in fact a mixture of two phases, ferrite and cementite $\left(\mathrm{Fe}_{3} \mathrm{C}\right)$. It forms by the cooperative growth of both of these phases at a single front with the parent austenite. As can be seen in Fig 13, the fraction of pearlite was mostly same

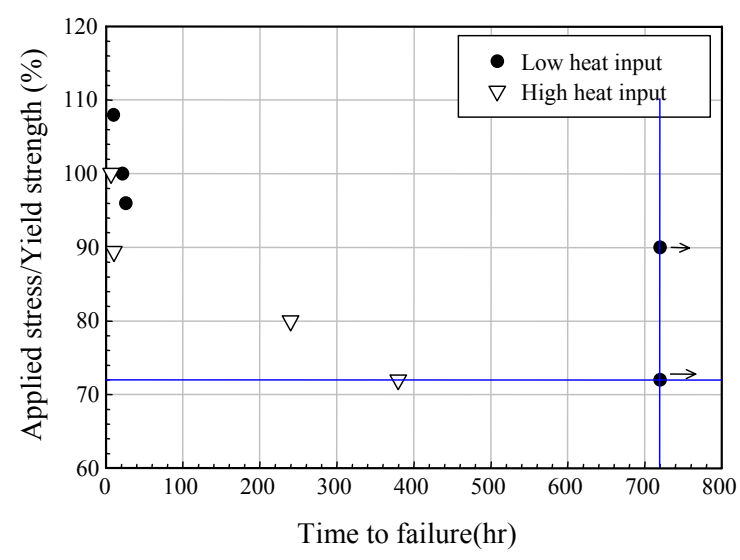

Fig. 11 SSC test results of API X65 grade steel weldment with heat input

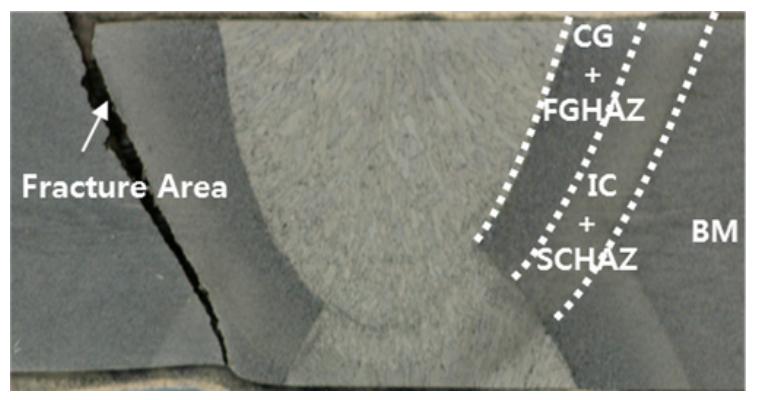

Fig. 12 The macrographs showing SSC tested specimens from low heat input weldment

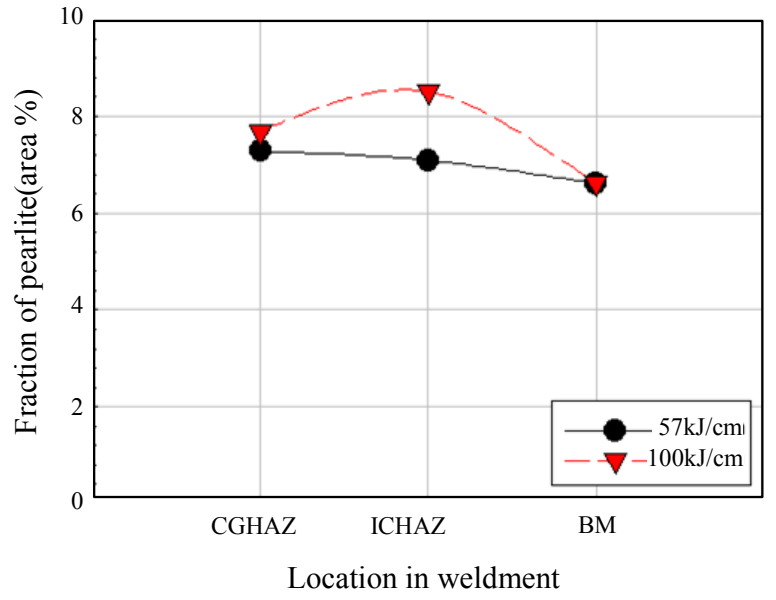

Fig. 13 Comparison of pearlite fraction for each heat input

for the CGHAZ and the base metal for the various heat inputs, but it differs in the ICHAZ region. .It can be seen that the larger the heat input in the ICHAZ region, the higher the fraction of pearlite. It is considered that the cooling rate is slowed due to the influence of high heat input and the generation and growth of pearlite are promoted. Also, the ICHAZ forms during peak temperature heating between approximately $730^{\circ} \mathrm{C}$ and $850^{\circ} \mathrm{C}$. It corresponds to the temperature at which a mixed structure of ferrite and cementite is formed at the Fe-C system. It is considered to be related to the SSC behavior of API X 65 steel weldment. This is because the pearlite can be a hydrogen trapping site that causes SSC. Fig. 14 shows the distributions of M-A constituents with weldment positions. There is no significant difference in the welds according to the heat input. However, the SSC lifetime of low heat input weld specimen is satisfied the NACE requirement. Therefore, the M-A constituent fraction was not related to the SSC behavior in this study.

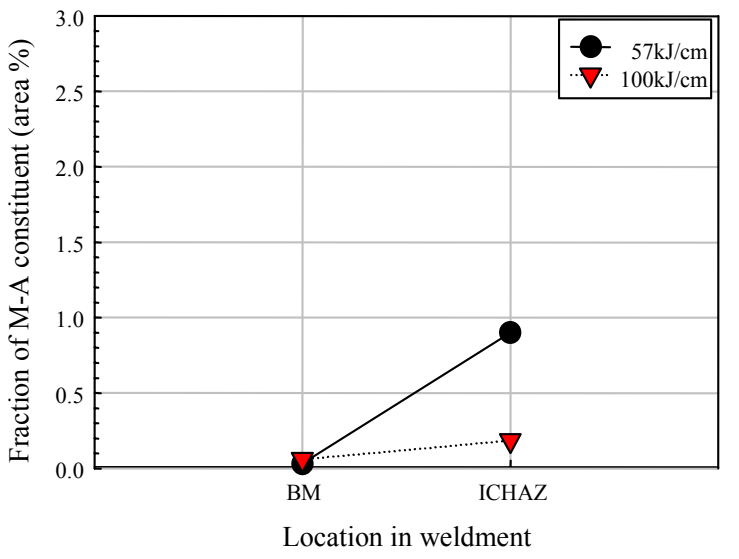

Fig. 14 Comparison of M-A constituent fraction for each heat input 


\section{Conclusions}

To investigate the SSC resistance of API X65 grade steel weldment, the effect of heat input was studied.

The main results are as follows:

1) In the low carbon TMCP steel, a localized softening occurred in ICHAZ region regardless of weld heat input. This may be attributed to ferrite grain coarsening and diminishing thermo-mechanical history of base metal during weld thermal cycle.

2) The softening ratio (ICHAZ Hv/Base metal Hv) in high heat input was 0.81 which indicated more severe hardness drop occurred in low heat input compared to the ratio of 0.86 . This may be attributed to the different weld input energies.

3) As a result of SSC test of API X65 steel weld, NACE requirement was satisfied at low heat input, but it was not satisfied at high heat input condition.

4) For the present low carbon TMCP type API X65 grade steel, SSC in the softened ICHAZ was the main form. So, a minimum HAZ hardness may be justified for these types of steels for sour services.

\section{Acknowledgments}

This study was conducted with specific foundation research support from KEIT (Korea Evaluation Institute of Industrial Technology).

ORCID: Byoung-Hyun Yoon: https://orcid.org/0000-0003-4683-7888

\section{References}

1. R. A. Carnerio, R.C. Ratnapuli and V. F Cunba Lins, The influence of chemical composition and microstructure of API linepipe steels on hydrogen induced cracking and sulfide stress corrosion cracking, Materials
Science and Engineering A, 357(2003), 104- 110 https://doi.org/10.1016/S0921-5093(03)00217-X

2. L.W. Tsay, Y.C. Chen and S.L.I. Chan, Sulfide stress corrosion cracking and fatigue crack growth of welded TMCP API 5L X65 pipe-line steel, International Journal of Fatigue, International Journal of Fatigue, 23(2001), 103-113 https://doi.org/10.1016/S0142-1123(00)00081-5

3. S. Endo, M. Nagae, Y. Kobayashi and, K. Ume, Sulfide stress corrosion cracking in welded joints of welded linepipes, ISIJ International, 34(1994), 217-223 https://doi.org/10.2355/isijinternational.34.217

4. G.M. Omweg, G.S. Frankel, W.A.Bruce,J.E.Ramirez, and G.Koch, Effects of welding parameters and H2S partial pressure on the susceptibility of welded HSLA steels to sulfide stress cracking, Welding Journal, 82 (2003), 136S-144S

5. Gyu young Lee and Dongho Bae, Assessment of the electrochemical corrosion properties and environmentally induced cracking of an A106 Gr B steel pipe weld in a $\mathrm{NaCl}$ solution saturated with $\mathrm{H} 2 \mathrm{~S}$ gas, Met. Mater. Int., 17 (2011), 341-347 https://doi.org/10.1007/s12540-011-0424-5

6. Hoi-SooRyoo, HeeJin Kim and Dong-Eon Lee, Evaluation of HIC/SSCC Resistance for API-X70 Pipe Manufactured by JCO Bending Process and SA Welding, Journal of Welding and Joining, 32(2014), 431-436 https://doi.org/10.5781/JWJ.2014.32.5.1

7. ISO 3183-1, Petroleum and natural gas industries-Steel pipe for pipelines-Technical delivery conditions, Part 1 : Pipes of requirement class A, (1996)

8. Takahiro Kushida, Yoshihiko Higuchi, and Mitsuhiro Numata, Akio Yamamoto, Kazushi Ohnishi, Akitoshi Teraguchi and Jun Fujino, Advanced Technologies of High Strength Linepipe for Sour Service, The Sumitomo Search 58(1996), 24-31 